\title{
Durability and service life prediction for concrete structures - developments and challenges
}

\author{
Mark G Alexander ${ }^{1}$ \\ ${ }^{1}$ University or Cape Town, Department of Civil Engineering, Cape Town, South Africa
}

\begin{abstract}
The paper reviews developments in service life prediction for concrete structures. It indicates the difficulties inherent in rational service life design, in view of the multiple factors and variabilities involved in the process. The paper also emphasises the advantages of performance-based approaches to durability prediction, and considers performance testing, which is critical to achieving intended service life. Such approaches allow service life modelling, which the current prescriptive approaches do not. The concept of 'durability indicators' is covered, with a practical example showing how this can be used to improve concrete durability in construction. The paper also stresses the importance of an 'integrated approach' to durability specifications, performance-based predictions, and site quality control.
\end{abstract}

\section{Introduction}

Concrete remains the material of choice for the vast majority of construction activities around the world. The reasons are obvious: it is economical, easy to use, can be shaped into endless forms, is excellent structurally, and, despite the claims that it is not a 'green' material, has a very low carbon footprint - see Table 1

Table 1. Environmental indicators of concrete and other materials

\begin{tabular}{|l|l|l|l|}
\hline & Concrete & $\begin{array}{l}\text { Fired clay } \\
\text { bricks }\end{array}$ & Steel \\
\hline $\begin{array}{l}\text { Embodied } \\
\text { energy }(\mathrm{MJ} / \mathrm{kg})\end{array}$ & $\sim 0.95$ & $\sim 3.00$ & $\sim 35$ \\
\hline $\begin{array}{l}\mathrm{CO}_{2} \text { emissions } \\
(\mathrm{kg} \mathrm{CO}\end{array}$ & $\sim 0.13$ & $\sim 0.22$ & $\sim 2.80$ \\
\hline
\end{tabular}

Concrete is also the 'developmental material' par excellence. Global development in infrastructure, housing, and so on is unthinkable in the absence of modern concrete. Further, concrete has today assumed a position of being a sophisticated material when used at the upper end of its technological usage scale, incorporating multiple binders, admixtures, fibres, various aggregates, and the like, to produce a composite material that can be tailored to almost any constructional requirement. At the other end of the technological scale, it remains accessible to the 'common person', helping her or him to improve their lives in meaningful ways.

Nevertheless, there are real challenges in taking concrete forward into future decades as the construction material of choice. One of the most pressing is the question of lack of durability, coupled with 'Design for Service Life', with the associated concepts of 'Performance-based design', particularly for durability.

\section{Design for service life}

Design for service life implies that we can, rationally, perform the necessary range of design activities that will give reasonable assurance that the structure in question will fulfil its intended function for the required service life. This may be feasible when the service life is 20 or 30 years, or maybe even 50 years, but, practically, how do we design for a 100 -y or $150-y$ service life? This is now being more regularly demanded by infrastructure owners. The following aspects need to be considered:

- Changing exposure environments (for example, global warming and related extreme weather events)

- Rapidly changing materials, especially with the pressure to reduce environmental impacts

- Inadequate knowledge and models

- The pervasive problem of variable construction quality

- Differing perceptions of what 'service life' means, particularly in terms of 'end of service life' criteria

- The physical impossibility of verifying our designs at an age much greater than 50 years!

Take for example the 'Coignet House' in Paris, built in 1853, and thought to be the first reinforced concrete house in the world, shown in Figure 1. It is clearly now in a poor state, with evidence of reinforcing corrosion and 
other deterioration. The question is: how would this structure have been designed in the 19th Century, to conform to the vastly different requirements of the $21^{\text {st }}$ Century? The house appears to be abandoned, implying that minimal or no maintenance has been carried out over, possibly, many decades. Despite this, the house is still standing - a mute testimony to the longevity of concrete!

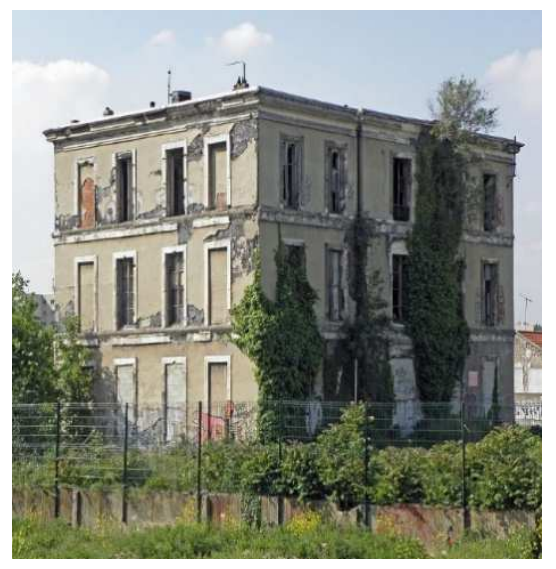

Fig. 1. Coignet house in Paris - the world's first reinforced concrete house, 1853

Engineers understand 'design \& specification', but usually these are embedded in national codes of practice, standard specifications, and design guidelines or rules. When it comes to service life deign, guidelines are largely non-existent, and the standards are wholly inadequate to provide for meaningful approaches. Since service life design, by definition, involves being able to 'predict' the behaviour or performance of a structure over a long period of time, specifically in terms of its ability to remain serviceable, it is obvious that 'Service Life Design' requires 'Service Life Models' that are adequately predictive. Thus, Service Life Modelling implies Service Life Prediction - and vice versa. And this is precisely where the problem lies - our general inability to do adequate service life modelling, because of our inadequate knowledge, but also importantly, because of the range of exposure conditions that might exist even in a single structure. Add to this variable construction quality, and this becomes quite an intractable problem!

Further salient points about 'service life design' are:

- Current approaches are inadequate or very basic

- Current approaches are almost universally 'prescriptive' in nature (see later)

- There is very little true 'durability design' carried out in practice, let alone Service Life Design

- Research has run well ahead of practical implementation

One major problem at present is the prescriptive nature of current approaches - dealt with in more detail later. It is essential that we move to 'performance-based' approaches if we hope to make progress in a reasonable time. First, however, other aspects of service life prediction and modelling are covered.

\subsection{Service Life Prediction (SLP) and Service Life Modelling (SLM)}

The essential elements in service life prediction and modelling are:

- Understanding of deterioration mechanisms

- Translation of deterioration mechanisms into mathematical models that can describe rates of deterioration and consequent structural damage: SLP is largely an exercise in determining rates of deterioration and damage

- Measurement of key material parameters - over time if needed; this means developing and implementing robust characterisation and quality control tests, which must be routine, easilycarried out, and represent reliable measures of resistance (e.g. to chloride ingress)

\subsection{Critique of current service life models}

Several general Service Life Models exist, such as DuraCrete, DURACON, LIFE-365, etc., but all still have shortcomings. Current SLMs can broadly be represented as those that are 'universal', such as the fib (Model Code) [1] and ISO [2], or those that are more 'local', such as LIFE365, DURACON, etc. The 'simpler' models cover limited exposure conditions, and are mainly related to reinforcement corrosion, being diffusion-based models. As such, they ignore other deterioration mechanisms such as AAR, scaling, sulphate attack, and so on.

The more 'sophisticated' model may cover other (but not all) types of chemical exposures, additional fluid transport mechanisms, and so on, but: they are not necessarily more accurate! Also, their assumptions and algorithms are usually difficult to verify independently.

All current models cannot deal adequately with the effects of construction or design defects, which is a major drawback. Further, they mostly do not fully consider the 'trade-off' between initial construction cost, and later maintenance or rehabilitation costs.

\section{Prescriptive vs performance approaches}

'Prescriptive' approaches, which are currently the norm, have already been mentioned. This section also briefly introduces the concept of performance approaches. The move to performance-based specifications (PBS) is gathering momentum, for example the NRMCA P2P initiative [3], and the French PERFDUB Programme [4]. Various national jurisdictions also have PBS in various stages of development - e.g. Canada, Spain, Switzerland, and South Africa.

The features of a prescriptive approach are that it sets limiting values, for example mix materials and proportions, it often prescribes construction processes such as curing, and it works on a 'deemed-to-satisfy' approach. The main disadvantages have long been recognised: primarily, that it does not permit, promote, or 'guarantee' a) in-situ verification of specified requirements, b) actual quality of construction, c) prediction for service life requirements, d) economic analysis or maintenance budgeting, and e) innovation. 
Further, in prescriptive approaches, there is frequently a major 'disconnect' between the intention of the owner or designer, as set out in the specification, and that actually achieved in construction. Figure 2 shows some results from our lab, plotting oxygen permeability index (OPI) measured on actual structures, against standard cube strength measured on the same concrete as used in the structures. It is clear there is no correlation!

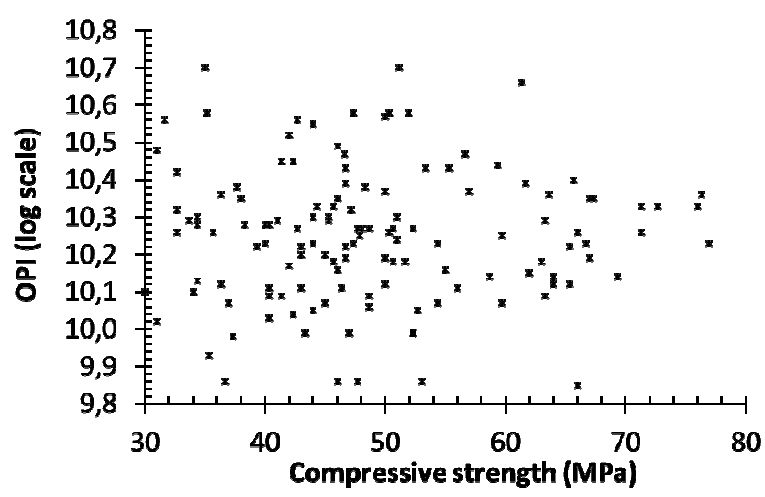

Fig. 2.Oxygen permeability index (OPI $(\log ))$ vs. cube strength, actual structures

\subsection{Responsibilities in prescriptive vs performance approaches}

In the prescriptive approach, since the 'owner' (or their agent such as the architect, engineer, etc.) specifies the mix, materials, properties etc., the owner also assumes full responsibility for the concrete. On the other hand, the performance approach requires the owner, contractor, and materials supplier to cooperate: a) the 'Owner' specifies required performance (e.g. concrete properties), b) the supplier is responsible for delivering the appropriate concrete, and c) the contractor is responsible for placing and curing the concrete to achieve the performance properties in situ. This implies a proper definition and division of responsibilities between the parties, for achieving concrete quality, see Figure 3.

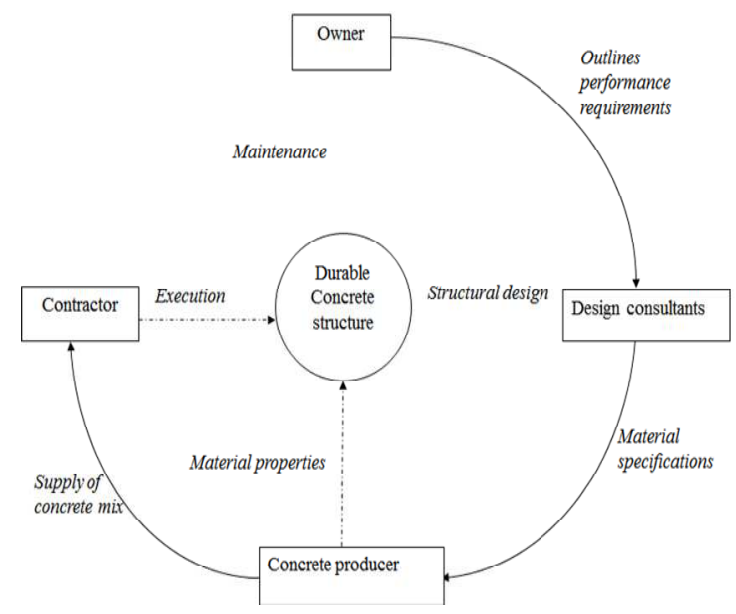

Fig. 3.Division of responsibility in a performance approach, to achieve a durable concrete structure

Note in Figure 3, that it is the finished concrete structure that is required to be durable, implying that ways must be found to assess the properties of the as-built structure. Many so-called 'performance-based approaches' do not address this critical element, and so should not be called such.

\subsection{Shift from prescriptive to performance approaches}

A move from 'prescriptive to performance' approaches is absolutely necessary to adopt SLP\&SLM methods. However, the shift will not be quick or easy, due to a) concrete industry conservatism, b) a lack of trained personnel to provide technical advice to specifiers and engineers, and c) a serious lack of quick, reliable durability tests, which are essential. Until such tests are developed and verified in practice, we may still have to rely on the "equivalent performance" concept (not covered here).

\section{Performance-based design approach}

In practice, performance approaches can represent either a partial approach (termed 'hybrid'), or a full performanceba sed approach. Both encompass key elements such as tests by which to characterise the desired performance, definition and specification of performance limits by which to judge acceptable performance, and, importantly, integration of durability requirements and durability design through service life models to estimate service life of the RC structure [5]. Crucially, in a full performance approach, specified concrete properties should be measurable in situ to ensure as-built quality is actually achieved. This leads to questions of performance testing and performance specifications.

\subsection{Performance testing and limits}

Performance testing requires development of reliable and representative test methods and the imposition of suitable performance limits. Performance tests may be used in different ways: for pre-qualification of mixes prior to construction where only the material 'potential' (in the sense of the ability of the material to potentially be durable) is proved; and for quality control (QC) during construction, where a) tests are carried out on concrete mixes 'as delivered', and b) tests are done on the actual structure, using in-situ tests or samples that are removed from the structure and tested in a laboratory. The object is to assess the actual as-built quality of the structure.

\subsection{Performance specifications}

In any methodology, the performance parameters and criteria for the structure must be explicitly described and quantified, and a conformity scheme must be set up to verify these parameters in practice and ensure the criteria are met. Thus, the performance specification must clearly describe (i) the functional requirements to ensure that the parties involved in their implementation do not interpret them differently; (ii) performance requirements for the structure, so that the concrete producer and constructor work together in the design of the concrete mix that will meet the performance requirements; (iii) means of 
verifying compliance using tests that are reliable, repeatable, accurate and preferably easily applicable on site; and (iv) a means to enforce compliance with the specifications, e.g. through penalties when specifications are not met.

\subsection{Hybrid approaches}

A 'hybrid' approach is a mix of prescriptive and performance elements, where greater emphasis should be placed on the performance criteria. The client and/or specifier decide on the desired level of performance in the given exposure conditions and propose relevant 'durability indicators' or other durability parameters which are used to prepare specifications. A hybrid approach may not explicitly address a design service life period; rather, it aims at achieving the relevant durability parameters that demonstrate the suitability of the concrete, including its composition, in relation to the exposure conditions.

\subsection{Durability indicators}

Durability indicators, or durability indexes, comprise physical, chemical, or electro-chemical parameters that characterise the concrete at an engineering level. They must be a) easily interpreted in an engineering context, such as being linked to a notional service life or rate of deterioration; b) easily measurable and reliably quantifiable to give engineers confidence in use in construction specifications; and c) sensitive to processing and environmental factors such as binder type, influence of SCMs, mix proportions, placing and compaction, and type and degree of curing.

Durability indicators are well-suited to permit characterisation of the concrete in terms of its potential to be durable - largely the constituent materials - and how these are processed to produce a concrete of the desired properties [6]. Durability indicators encompass a wide scope, e.g. direct measures of permeability, conductivity or the like; indirect measures such as calcium hydroxide residualsor porosity indexes; or chemical/electrochemical properties that provide an indication of potential durability. It is critical that the relevant deterioration mechanisms be considered: durability, however described or characterised, relates to a governing deterioration mechanism.

In summary, the following points are important regarding performance-based approaches:

- A means of relating actual performance to quality control tests (e.g. in terms of limiting material parameters)

- Conformity criteria and procedures, which must be calibrated against known performance measures or traditional solutions

- An "Integrated Scheme" in which the relevant material parameters can be used in quality control, service life modelling (prediction), and setting of specification limits

- Finally, the issue of actually assessingin-situ durability properties. This is a thorny issue, and likely to be so for many years to come.

\section{Practical implementation}

\subsection{Limit states for durability, and service life design approaches}

Practical implementation of a performance-based approach incorporating service life assessment and codification requires the following elements (as already mentioned): (i) quantifiable limit state criteria, with physical meaning; (ii) a defined service life; (iii) deterioration models with parameters that directly or indirectly are linked to the performance criteria; (iv) compliance tests; (v) a strategy for maintenance and repair; and (vi) quality control systems.

Engineers mostly work to codes of practice, making it essential that any usable approach be codified. Structural codes, which include durability provisions, are slow in being updated, so that new knowledge from research and practice takes a long time to find its way into the standards. However, as an example of implementation of performance-based durability design, ISO 13823 [2] outlines a limit-state methodology which is related to different service life design approaches (not covered here); this methodology has been taken up in the 2010 fib Model Code [1], with the approaches to service life design being (i) Full probabilistic approach; (ii) Partial safety factor approach, (iii) Deemed-to-satisfy approach, and (iv) Avoidance of deterioration approach.

The fib Model Code approach has merit in moving away from the current simplistic approaches. However, for many if not most RC structures, a minimalist approach may be adequate - since many structures are not exposed to severe environments that threaten their longevity, or are not intended to have long service lives. For mild or nonaggressive environments, simple attention to good construction practices, which should include good mix design, compaction and curing, should help to ensure adequate durability.

\subsection{Practical example of implementation, using a durability index performance-based approach}

In South Africa, we have developed and implemented a 'durability index performance-based approach', for various infrastructure projects. It is based on measurement of so-called durability indexes, of which one is the oxygen permeability index (OPI). For structures located inland, a limit OPI value is provided. In one study [7], OPI test variability for different sub-projects of a large construction project was measured, and compliance with the set limit value of 9.70 (log scale) determined. OPI variability was observed to be high for in situ structures, but lower for precast elements - see Figure 4. Clearly, with proper control of construction practices (placing, curing and compaction), the required durability properties of a structure can be obtained. The implementation example serves to stress the importance of as built verification, and the difficulty of controlling quality on site. 

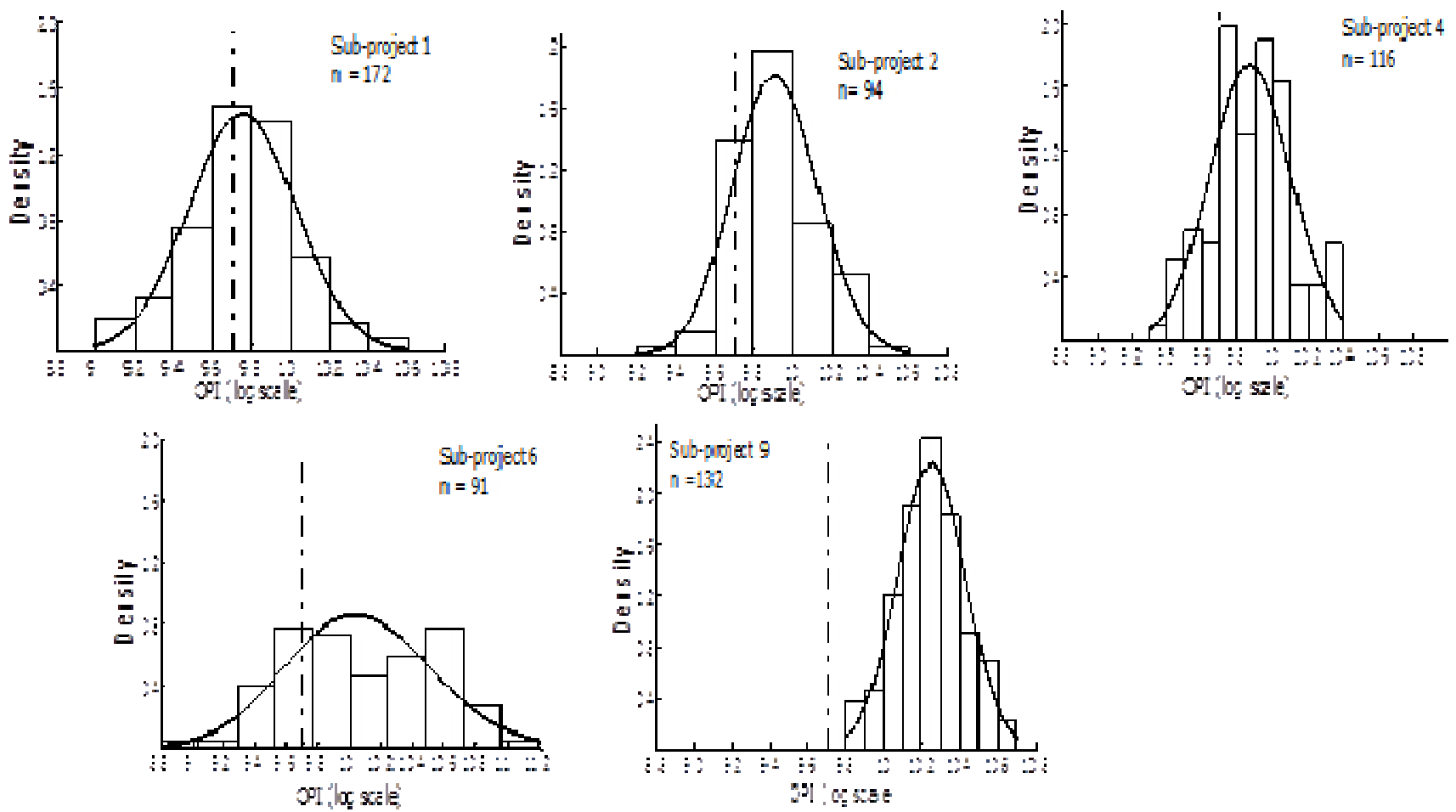

Fig. 4. Illustration of variability in OPI values for different sub-projects. Variability is high for in situ structures (subprojects 1, 2, 4 and 6) and low for precast structures (sub-project 9)

\section{Closure}

The paper has briefly outlined issues around design for service life in reinforced concrete structures, related to ongoing problems in concrete durability. Implementation of 'service life design' cannot occur in the absence of a move to performance-based approaches to design and specification, since the current prescriptive approaches preclude development of more advanced methods. Service life design implies the ability to do service life prediction and modelling; however, at this stage, we are still a long way off comprehensive models that are reliable and accurate. The problem is compounded by the variety of exposure environments for concrete structures, and which are difficult to quantify. However, pragmatic approaches have been developed that can make a significant difference to improving durability performance, and certainly more work is needed at such local and hybrid levels.

\section{References}

1. fib Model Code. (2010)Model code for concrete structures, Ernst \& Sohn, 402 pp.

2. ISO 13823-1 General Principles on the design of structures for durability. Geneva. International Organization for Standardization, 2008.

3. C. Lobo, L. Lemay, and K. Obla (2005). Performancebased specifications for concrete, The IndianConcrete Journal, 79(12), 13-17

4. L. Linger \&F. Cussigh(2018). PERFDUB: A New French Research Project on Performance-Based Approach for Justifying Concrete Structures Durability. In High Tech Concrete: Where
Technology and Engineering Meet.1. https://doi.org/10.1007/978-3-319-59471-2

5. M.G. Alexander and M. Santhanam (2013) Achieving durability in reinforced concrete structures: durability indices, durability design and performance-based specifications. International Conferences on Advances in Building Sciences \& Rehabilitation and Restoration of Structures, Feb 2013, IIT Madras, Chennai, India, 2012, 21pp.

6. M.G. Alexander, Y. Ballim, and K. Stanish (2008).A framework for use of durability indexes in performance-based design and specifications for reinforced concrete structures. Materials \& Structures, 41(5),921-936.

7. G. Nganga, M.G. Alexander and H. Beushausen (2013).Practical implementation of the durability index performance-based design approach. Construction \& Building Materials, 45,251-261. 